\title{
The effect in sheep of physical form on the sites of digestion of a dried lucerne diet
}

\author{
1. Sites of organic matter, energy and carbohydrate digestion
}

\author{
By D. J. THOMSON,* D. E. BEEVER,* J. F. COELHO DA SILVA† \\ AND D. G. ARMSTRONG \\ Department of Agricultural Biochemistry, University of Newcastle upon Tyne
}

$$
\text { (Received } 5 \text { fuly 1971 - Accepted } 23 \text { December 1971) }
$$

I. 'The effect of altering the physical form of a regrowth crop of dried lucerne (Medicago sativa L. var. Chartainvilliers) on the sites of organic matter, energy and carbohydrate digestion was studied with sheep fitted with re-entrant cannulas at the proximal duodenum and at the terminal ileum.

2. Chopped, cobbed, and ground and pelleted diets with moduli of fineness of $3 \cdot 5,2 \cdot 7$ and $I \cdot 5$ respectively were prepared from the same high-temperature dried crop and given twice daily to sheep at a level of intake of $910 \mathrm{~g}$ dry matter/d.

3. Physical form did not affect the apparent digestibility of the organic matter. On the cobbed and pelleted diets losses of digestible organic matter before the small intestine were significantly lower $(P<0.05 ; P<0.001$ respectively) and losses in the small intestine were significantly higher $(P<0.05)$ than for the chopped diet.

4. Apparent digestibility of the gross energy of the three physical forms was similar, but the flow of energy into, and digestion within, the small intestine were markedly greater $(P<0.05)$ for the ground and pelleted diet than for either the chopped or cobbed diet, for which the values did not differ. Energy digestion in the caecum and colon was similar for the three physical forms.

5. Total cellulose and hemicellulose digestibilities were not affected by processing, but the proportion of the digestible cellulose and digestible hemicellulose digested in the fore-stomachs of sheep given the ground and pelleted diet (63 and $55 \%$ respectively) was less than for the chopped diet $(85$ and $68 \%)$. The digestibility of the cobbed diet was intermediate. Digestion in the caecum and colon compensated for these differences in digestion of cellulose and hemicellulose in the fore-stomachs.

6. Volatile fatty acid (VFA) concentration in the rumen liquor was lower in sheep given ground, pelleted lucerne than in those on the chopped diet, but the VFA proportions were very similar. The implications of the change in site of energy and carbohydrate digestion with grinding and pelleting are discussed.

The nutritional evaluation of processed forage crops has been the subject of investigation for some considerable time. Experiments examining the effects of altering the physical form of the diet on voluntary food intake, apparent digestibility, energy utilization and animal production with processed forage diets given alone, or in combination with other feeds, have been reviewed by Minson (1963), Moore (1964), Beardsley (1964) and Meyer, Kromann \& Garrett (1965).

Previous work has shown that voluntary food intake of forage diets is normally increased when the forage is ground and pelleted (Meyer, Gaskill, Stoewsand \& Weir, I959), and apparent digestibility is generally depressed (Blaxter \& Graham, 1956). The extent of these increases in voluntary food intake and depressions in apparent digesti-

* Present address: The Grassland Research Institute, Hurley, Berkshire.

† Present address: Department de Zootecnia, Universidade Federal de Vicosa, Minas, Brazil. 
bility are influenced by several factors: the stage of maturity and digestibility of the crop (Meyer, Weir, Jones \& Hull, 1960); the species and variety of the forage crop (Heaney, Pigden, Minson \& Pritchard, I 963), and in particular whether it is grass or legume (Thomson \& Cammell, I972); the plane of nutrition at which the diet is fed (Blaxter \& Graham, 1956); the fineness of grinding of the forage (Rodrigue \& Allen, I960). Forbes, Fries \& Braman (1925) examined calorimetrically the net energy values of chopped and ground lucerne. Blaxter \& Graham (I956) examined grass given chopped, or ground to two different degrees of fineness and pelleted. Neither for the low-digestibility lucerne used by Forbes et al. (1925), nor for the high-digestibility grass used by Blaxter \& Graham (1956), did changes in the physical form of the diet affect the net energy content. However, Paladines, Reid, van Niekerk \& Bensadoun (I964) found a higher net energy value for timothy hay in the ground and pelleted form, compared with the long form, using the comparative slaughter technique.

In all these experiments, as in that reported by Balch, Broster, Rook \& Tuck (1965), in which hay in long and ground forms, and ground maize cooked or raw were used, depressions in the metabolizable energy content of the ground, pelleted diets were found, but the metabolizable energy of the processed diets was utilized with greater efficiency than that of the long or chopped diets for growth and lipogenesis.

The total times spent eating and ruminating are less on ground, pelleted diets than on long or chopped diets (Balch, I969). Rumen $\mathrm{pH}$, methane production, the production and proportions of rumen volatile fatty acids (VFA), rate of digestion within the rumen and the rate of passage from the rumen of undigested feed particles have all been shown to be influenced by the physical form of the forage diet (Meyer et al. 1965).

The response of the ruminant animal to ground and pelleted forage diets, contrasted with the same diet given in the long or chopped form, has many features of physiological and biochemical interest, and recent studies by Hogan \& Weston (I967) have examined the effects of the physical form of forage diets on digestion within the alimentary tract.

Technical advances in the processing of dried forage crops have led to the introduction of diets for ruminants in physical forms that are intermediate between chopped and finely ground diets. In cobs and wafers some proportion of forage staple is retained.

In the present experiment the extent of digestion in the rumen and that occurring post-ruminally, of the organic matter, energy and carbohydrate constituents of a dried lucerne (Medicago sativa L.) diet offered in three different physical forms - chopped, cobbed and pelleted - was assessed quantitatively using sheep fitted with re-entrant cannulas at the proximal duodenum and at the terminal ileum. Preliminary study (Thomson \& Cammell, 1972) of these dried-lucerne diets had indicated a slight depression in the energy digestibility of the ground and pelleted diet due primarily to plane of nutrition. Feeding at a controlled level of food intake with these lucerne diets did appear to offer the opportunity of establishing whether there were differences in the site of digestion within the ruminant alimentary tract not associated with a concomitant depression in total apparent digestibility. A preliminary report of this work has been published (Thomson, Beever, Coelho da Silva \& Armstrong, 1969). The 
chopped, and the ground and pelleted diets were also used in an assessment by the comparative slaughter technique of the efficiency of utilization of the dietary energy (Thomson \& Cammell, 1972).

\section{EXPERIMENTAL}

\section{Preparation of diets}

A regrowth of lucerne (Medicago sativa L. var. Chartainvilliers) dried commercially in a high-temperature, pneumatic drum-drier (British Crop Driers, Navenby, Lincolnshire) was used to prepare diets of three different physical forms from the same crop. The diets were (I) chopped - chop length of stems $6 \mathrm{~cm}$; (2) cobbed - prepared by compressing the chopped material into cylindrical cubes (cobs) of approximately 2.5 $\mathrm{cm}$ in diameter and $2.5 \mathrm{~cm}$ in length; and (3) pelleted - prepared by grinding the chopped lucerne through a $2 \mathrm{~mm}$ screen before extrusion as pellets $\mathrm{I} \cdot 2 \mathrm{~cm}$ in diameter and $2.5 \mathrm{~cm}$ in length. The physical form of the lucerne diets was altered by the processing imposed on the dried crop.

\section{Sheep}

Four mature castrated male sheep (Suffolk $\times$ Halfbred), 2.5 years old and weighing between 45 and $50 \mathrm{~kg}$, were used. Each sheep was fitted with a rumen cannula, and with re-entrant cannulas at both the proximal duodenum and the terminal ileum, using the technique of Brown, Armstrong \& MacRae (I968). The same three sheep received the chopped and cobbed lucerne diets, but one of these sheep had large feed refusals on the pelleted lucerne and was replaced by a fourth.

\section{Management of animals}

During the experimental periods, the sheep were housed in metabolism crates in a controlled environment with a $\mathrm{I}_{4} \mathrm{~h}$ daily lighting pattern and an ambient temperature of $13-16^{\circ}$. All the sheep were housed in exercise pens with slatted floors between experiments.

The sheep were given each of the three diets at the same level of dry-matter intake $(910 \mathrm{~g} / \mathrm{d})$. The food was given in two equal meals at 09.00 and $\mathbf{1} 6.00$ hours. At each feeding $3 \mathrm{~g}$ of paper impregnated with chromic oxide were administered (Corbett, Greenhalgh, McDonald \& Florence, r960) through the rumen fistula. This treatment was continued for at least $\mathrm{i} 4 \mathrm{~d}$ before the collection of digesta samples. Distilled water was freely available at all times and consumption was recorded daily. No additional minerals were supplied to the animals.

\section{Collection of samples}

Faecal and digesta samples were collected and prepared for analysis by the method previously described (Beever, Thomson, Pfeffer \& Armstrong, r97r). Faecal collections were made for a period of $7 \mathrm{~d}$, and were followed by $24 \mathrm{~h}$ total collections, first of ileal and then of duodenal digesta. The shortest interval of time between ileal and duodenal collections was $2 \mathrm{~d}$. All the values relating to duodenal and ileal flows were corrected to mean $24 \mathrm{~h}$ values on the basis of $100 \%$ recovery of chromic oxide (MacRae \& Armstrong, I $969 a$ ). Rumen liquor samples were removed by vacuum 
Table I

(a) Composition and physical characteristics of the dried lucerne diets

\begin{tabular}{|c|c|c|c|c|c|c|c|}
\hline & $\begin{array}{c}\text { Organic } \\
\text { matter } \\
\text { (g/roog DM) }\end{array}$ & 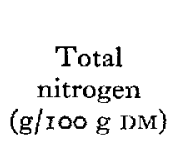 & $\begin{array}{c}\text { Cellulose } \\
\text { (g/100 g DM) }\end{array}$ & $\begin{array}{c}\text { Hemi- } \\
\text { cellulose } \\
(\mathrm{g} / \mathrm{l} 00 \mathrm{~g} \text { DM })\end{array}$ & $\begin{array}{c}\alpha \text {-Linked } \\
\text { glucose } \\
\text { polymer } \\
\text { (g/roo g DM) }\end{array}$ & $\begin{array}{c}\text { Gross } \\
\text { energy } \\
\text { (kcal/g DM) }\end{array}$ & $\begin{array}{c}\text { Gross } \\
\text { energy } \\
(\mathrm{kJ} / \mathrm{g} \mathrm{DM})\end{array}$ \\
\hline Chopped & $9 \mathrm{I}_{4} \cdot 4$ & 2.55 & $29 \cdot 3$ & II $\cdot 9$ & 4.08 & $4 \cdot 45$ & 18.6 \\
\hline Cobbed & 90.9 & $2 \cdot 92$ & $27 \cdot 6$ & $12 \cdot 3$ & $3 \cdot 14$ & $4 \cdot 52$ & 18.9 \\
\hline Pelleted & $91 \cdot 3$ & $2 \cdot 85$ & $28 \cdot 4$ & 12.0 & $2 \cdot 48$ & $4 \cdot 37$ & $18 \cdot 3$ \\
\hline
\end{tabular}

(b) Particle-size distribution (\% retained in each sieve)

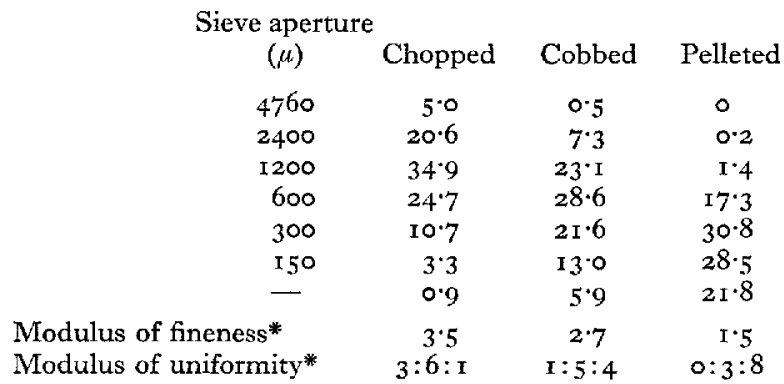

DM, dry matter.

* Derived from the measurements of particle size distribution by the method of the American Society of Agricultural Engineers (1967).

pump at $2 \mathrm{~h}$ intervals over a further $24 \mathrm{~h}$ period and strained through muslin; $25 \mathrm{ml}$ of the liquor were deproteinized with $5 \mathrm{ml} 2 \cdot 5 \mathrm{M}-\mathrm{H}_{2} \mathrm{SO}_{4}$ saturated with $\mathrm{MgSO}_{4}$. After filtering, the samples were frozen and kept until required for analysis.

\section{Analysis of samples}

Organic matter was determined as loss in weight of material dried at $100^{\circ}$ after ashing in a muffle furnace at $550^{\circ}$ for at least $4 \mathrm{~h}$. Gross energy was determined in an adiabatic bomb calorimeter (A. Gallenkamp \& Co., London), chromic oxide by the method of Stevenson \& de Langen (1960) and total nitrogen by macro-Kjeldahl. Cellulose content was determined by the method of Crampton \& Maynard (1938) and hemicellulose by the method described by Beever et al. (1971). $\alpha$-Linked glucose polymer was determined by the method of MacRae \& Armstrong (1968). The modulus of fineness (MF) and modulus of uniformity (MU) were derived from the measurements of particle size distribution made by the American Society of Agricultural Engineers (1967) method. The concentration of total VFA and molar proportions of VFA in the rumen contents were measured on a Pye ro4 gas-liquid chromatograph equipped with a flame-ionization detector and a 'phase-sep' universal support coated with Carbowax $20 \mathrm{M}$ terminated with terephthalic acid.

\section{RESULTS}

Table I $(a)$ shows the chemical composition of the three diets used. The nitrogen content of the cobbed and pelleted diets was less than that of the chopped. The three diets were very similar with regard to other constituents. 
Table 2. Mean quantities of organic matter present in the feed, entering and leaving the small intestine, and in the faeces of three sheep* given chopped, cobbed and pelleted lucerne

(The values for digesta at the duodenum and ileum have been adjusted for $100 \%$ recovery of chromic oxide. Mean values for the disappearance of apparently digested organic matter before and in the small intestine and in the caecum and colon are also given)

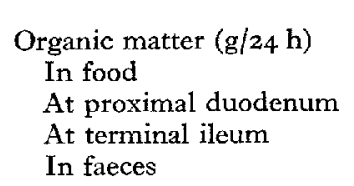

\begin{tabular}{|c|c|c|c|}
\hline Chopped & Cobbed & Pelleted & SEM \\
\hline $834: 3$ & $824 \cdot 4$ & $825 \cdot 5$ & - \\
\hline $595^{\circ} 2$ & 609.5 & $6.57 \cdot 8$ & - \\
\hline $465 \cdot 3$ & $43 r \cdot 8$ & $447 \cdot 2$ & - \\
\hline $328 \cdot 4$ & $323 \cdot 2$ & 3257 & - \\
\hline $60 \cdot 6$ & $6 \times \circ$ & $60 \cdot 5$ & 0.59 \\
\hline $47 \cdot 3$ & $42 \cdot 9$ & $33 \cdot 6$ & $2 \cdot 38$ \\
\hline $29^{\circ} 4$ & $36 \cdot 8$ & $42 \cdot I$ & $I \cdot 6 x$ \\
\hline $23 \cdot 3$ & $20 \cdot 3$ & 243 & I'I I \\
\hline
\end{tabular}

Apparent digestibility of organic matter (\%)

Disappearance of apparently digested organic matter $(\%)$

Before small intestine

In small intestine

In caecum and colon

$23 \cdot 3$

$20 \cdot 3$

$24 \cdot 3$

I. I I

* The values for the chopped and cobbed diets are derived from the same three sheep; a fourth, substitute, sheep was required for the pelleted diet.

Table 3. Mean quantities of gross energy present in the feed, entering and leaving the small intestine, and in the faeces of three sheep* given chopped, cobbed and pelleted lucerne

(The values for digesta at the duodenum and ileum have been adjusted for $100 \%$ recovery of chromic oxide. Mean values for the disappearance of apparently digested energy before and in the small intestine and in the caecum and colon are also given)

Gross energy $(\mathrm{kcal} / 24 \mathrm{~h})$

In food

At proximal duodenum

At terminal ileum

In faeces

Apparent digestibility of gross energy (\%)

$\begin{array}{lcccc} & \text { Chopped } & \text { Cobbed } & \text { Pelleted } & \text { SEM } \\ & & & & \\ 4062 & 4102 & 3950 & - \\ 3176 & 305^{8} & 3419 & - \\ 2402 & 2225 & 2252 & - \\ & 1769 & 1649 & 1667 & - \\ & 56.5 & 59.8 & 57 \cdot 8 & 0.65 \\ & & & & \\ \text { energy }(\%) & 38.6 & 42.5 & 23.3 & \mathbf{I} \cdot 42 \\ & 33.8 & 34.0 & 51.1 & 2.67 \\ & 27.6 & 23.5 & 25.6 & \mathbf{1} \cdot 64\end{array}$

Disappearance of apparently digested energy $(\%)$

Before small intestine

In small intestine

In caecum and colon

* The values for the chopped and cobbed diets are derived from the same three sheep; a fourth, substitute, sheep was required for the pelleted diet.

Table I $(b)$ contains the measurements of particle size distribution and the derived values for the modulus of fineness and the modulus of uniformity. The modulus of fineness is derived from the percentage of material on each screen and expresses the fineness of ground feeds for ruminants. Very finely ground forage can have an $\mathrm{MF}$ value of approximately $\mathbf{I} \cdot 0$, chopped grass of intermediate digestibility may have an MF value in the region of 4,5 . The modulus of uniformity complements the MF and expresses the proportion of coarse, medium and fine particles in ro parts of the feed, thus giving some indication of the uniformity of particle size distribution. Grinding the dried lucerne through a $2 \mathrm{~mm}$ screen and pelleting reduced MF from $3 \cdot 5$ for the chopped lucerne to $I \cdot 5$ for the pelleted diet. The proportion of fine particles in the pelleted diet (8) is considerably higher than the proportion in the chopped diet (I). The cobbed diet, prepared by compressing the chopped dried lucerne into cobs 
Table 4. Mean quantities of cellulose present in the feed, entering and leaving the small intestine, and in the faeces of three sheep* ${ }^{*}$ given chopped, cobbed and pelleted hucerne

(The values for digesta at the duodenum and ileum have been adjusted for $100 \%$ recovery of chromic oxide. Mean values for the disappearance of digested cellulose before and in the small intestine and in the caecum and colon are also given)

Cellulose $(g / 24 \mathrm{~h})$

In food

At proximal duodenum

At terminal ileum

In faeces

Apparent digestibility of cellulose (\%)

$\begin{array}{cccc}\text { Chopped } & \text { Cobbed } & \text { Pelleted } & \text { SEM } \\ & & & \\ 273.6 \dagger & 256.1 \dagger & 262.7 \dagger & - \\ 138.2 & 134.7 & 164.6 & - \\ 143.9 & 139.2 & 150.2 & - \\ 115.0 & 103.9 & 107.5 & - \\ 58.0 & 59.5 & 59.0 & 0.44 \\ & & & \\ 85.4 & 79.8 & 63.3 & 1.84 \\ -3.7 & -3.0 & 9.2 & 0.93 \\ 18.3 & 23.2 & 27.5 & 0.93\end{array}$

Disappearance of digestible cellulose $(\%)$

Before small intestine

In small intestine

In caecum and colon

$-3 \cdot 7$
I $8 \cdot 3$

$23 \cdot 2$

0.93

* The values for the chopped and cobbed diets are derived from the same three sheep; a fourth, substitute, sheep was required for the pelleted diet.

+ Includes $6 \mathrm{~g}$ administered with the chromic oxide pellet.

without grinding through a screen, gave an MF value of $2 \cdot 7$ and an MU of $1: 5: 4$ which is intermediate between the chopped and ground, pelleted diets.

Table 2 shows the flow of organic matter through the tract and the sites of disappearance of the digestible organic matter (DOM) for the three diets.

The standard errors presented in Table 2 (and in Tables $3^{-5}$ ) are for three diets and three sheep; there were no differences $(P<0.05)$ between sheep for the sites of digestion of any of the constituents examined.

Compared with the loss on the chopped form, the loss of DOM in the reticulo-rumen was reduced on the cobbed material $(P<0.05)$ and markedly so on the pelleted (pelleted $v$. chopped, $P<0.001$; pelleted $v$. cobbed, $P<0.01$ ). Losses of DOM in the small intestine with both the pelleted and cobbed diets were significantly higher than with the chopped material (chopped $v$. cobbed or pelleted, $P<0.05$ ), there being no significant difference between losses with the cobbed and pelleted materials. There were no significant differences due to physical form in the magnitude of the losses of DOM occurring in the caecum and colon.

Table 3 gives the results for the flow and digestion of the gross energy contained in the three diets. The apparent digestibility of energy did not differ between the three physical forms of dried lucerne when they were given at the same level of intake.

The extent of energy digestion at each site within the alimentary tract was very similar for the chopped and cobbed diets, but grinding and pelleting induced major changes in the site of energy digestion. The flow of energy into, and digestion within, the small intestine were both markedly greater $(P<0.05)$ with the ground and pelleted diet than with either the chopped or cobbed diet. In contrast, energy digestion in caecum and colon was similar for the three physical forms.

Therc was no difference in the total digestibility of cellulose on the three dicts, but the extcnt of digestion within the rumen and the caecum was affected by the physical form of the diet (Table 4 ). Grinding and pelleting significantly depressed cellulose 
Table 5. Mean quantities of hemicellulose present in the feed, entering and leaving the small intestine, and in the faeces of three sheep* given chopped, cobbed and pelleted lucerne

(The values for digesta at the duodenum and ileum have been adjusted for roo \% recovery of chromic oxide. Mean values for the disappearance of digestible hemicellulose before and in the small intestine, and in the caecum and colon are also given)

Hemicellulose $(\mathrm{g} / 24 \mathrm{~h})$

In food

At proximal duodenum

At terminal ileum

In faeces

Apparent digestibility of hemicellulose (\%)

$\begin{array}{rrrr}\text { Chopped } & \text { Cobbed } & \text { Pelleted } & \text { SEM } \\ & & & \\ \text { I08.6 } & \text { I I I.I } & \text { I08.8 } & - \\ 69.8 & 73.5 & 76.0 & - \\ 69.2 & 73.3 & 73.8 & - \\ 52.0 & 53.5 & 49.4 & - \\ 52.1 & 51.8 & 54.6 & \text { I.52 } \\ & & & \\ 68.5 & 65.5 & 55.2 & 5.19 \\ 1 \cdot 0 & 0.4 & 3.7 & 2.03 \\ 30.5 & 34.1 & 4 I \cdot 1 & 4.21\end{array}$

Disappearance of digestible hemicellulose $(\%)$

Before small intestine

In small intestine

In caecum and colon

* The values for the chopped and cobbed diets are derived from the same three sheep; a fourth, substitute, sheep was required for the pelleted diet.

Table 6. Total volatile fatty acid (VFA) concentrations (mmolll) and the proportions (molar \% basis) in the rumen liquor of sheep fed on dried lucerne, in a chopped or a ground and pelleted form

(Mean values with their standard errors for two sheep)

Diet Total VFA Acetic Propionic Isobutyric Butyric Isovaleric Valeric

Chopped lucerne $\quad 97.8 \pm 8 \cdot 0 \quad 61 \cdot 9 \pm 0.41 \quad 25 \cdot 2 \pm 0.68 \times \cdot 55 \pm 0.228 .58 \pm 0.38 \times \cdot 68 \pm 0.37 \times \cdot 08 \pm 0.08$ Pelleted lucerne $\quad 82.5 \pm 9.0 \quad 64 \cdot 0 \pm 0.7$ I $24 \cdot 2 \pm 0.60$ I.70 $20.377 .88 \pm 0.26$ I.43 $\pm 0.500 .76 \pm 0.06$

digestion before the small intestine $(P<0 \cdot 01)$; more cellulose was digested in the caecum and colon of shcep given this diet than with either the chopped $(P<0 \cdot 0$ I) or the cobbed $(P<0.05)$ diet. Some digestion of cellulose occurred during the passage of digesta from the duodenum to the terminal ileum in sheep given the ground and pelleted diet.

Hemicellulose digestibility (Table 5) was not influenced by the physical form of the diet. Although a trend was noted towards reduced digestion of hemicellulose in the rumen, and increased digestion in the caecum and colon, with increasing proportion of fine particles in the diet, none of the differences measured was significant. Between 30 and $40 \%$ of the digestible hemicellulose was digested in the caecum and colon.

Table 6 includes the mean total VFA concentrations and the individual VFA proportions in the rumen liquor samples withdrawn at $2 \mathrm{~h}$ intervals throughout a $24 \mathrm{~h}$ period from sheep fed on the chopped and on the ground, pelleted diets. The results of this comprehensive sampling over the full $24 \mathrm{~h}$ period showed no difference in the relative proportions of the different VFA produced in the ruminal digestion of these two forms of dried lucerne. The results for total VFA indicate that the quantity of VFA produced in the rumen was lower in the sheep fed on the ground, pelleted lucerne than in those fed on the chopped. 


\section{DISCUSSION}

The results of this experiment have demonstrated a marked effect of grinding and pelleting on the sites of digestion of organic matter, energy and carbohydrate of a dried crop of regrowth lucerne when compared with the same lucerne offered in the chopped form. The same feed was also compressed into cobs in which the size of the particles was intermediate between those present in the pellets and in the chopped material. The pattern of energy digestion within the alimentary tract of sheep given the cobbed diet was similar to that for sheep given the chopped lucerne diet. However, for cellulose and hemicellulose contained in the cobbed diet the extent of digestion of these fractions in the rumen and in the caecum was intermediate between the chopped and the ground, pelleted diet.

The digestion of cellulose and hemicellulose in the caecum and colon was considerable even on the chopped lucerne diet. Increasing the proportion of fine particles in the diet by cobbing and further by grinding led to increases in the digestion of cellulose and hemicellulose in the caecum and colon. Physical enlargement of the caecum has been noted in lambs fed on ground, pelleted diets when compared with the physical dimensions of that organ in lambs fed on the same diet in the chopped form (J. H. D. Prescott, personal communication; Thomson \& Cammell, 1972).

These results with dried lucerne confirm that grinding and pelleting alters the extent and site of digestion in the alimentary tract of the ruminant. Measurements of the rate of passage of material through the alimentary tract and derived estimates of the rate of passage from the rumen (or retention time) have been limited in that the results derived by use of the stained particle technique refer to the undigested portions of the diet (Balch \& Campling, 1965 ; Blaxter, Graham \& Wainman, 1956).

The apparent digestibility of the gross energy in the chopped and in the ground pelleted lucerne diets was very similar. However, the proportion of the energy digested before the small intestine was considerably lower on the pelleted diet, and energy digestion in the caecum and colon did not differ (Table 3). The rumen and the caecum are the sites within the alimentary tract of the ruminant at which the VFA are the main end-products of digestion. Leng (1970) has shown the concentration of VFA in the rumen to be related to VFA production. In the absence of a direct measure of VFA production rate for these diets the reduced VFA concentration in the rumen of sheep given ground, pelleted lucerne is indicative of a lower production of VFA. A lower ruminal VFA production rate has been measured with grinding and pelleting a diet of red clover (Trifolium pratense L.), using the isotope dilution technique (Beever, Thomson \& Harrison, I972).

The results reported here for artificially dried lucerne differ, however, from those derived from other studies with grass hays, dried grass and cercal-based diets. With the latter diets some $60-70 \%$ of the digested organic matter or gross energy was digested in the fore-stomachs of sheep (Hogan \& Phillipson, 1960; Bruce, Goodall, Kay, Phillipson \& Vowles, 1966; Beever et al. 197r; MacRae \& Armstrong, 1969 $b$; Topps, Kay \& Goodall, I968). In the present study the proportion of DOM disappearing in the fore-stomach ranged from 34 to $47 \%$. On the pelleted feed some $42 \%$ 
of the DOM was lost in the small intestine. When equal quantities of digestible energy were offered, this same ground and pelleted lucerne was utilized more efficiently for growth, carcass gain and wool production (Thomson \& Cammell, 1972).

The results of Hogan \& Weston (1967) are capable of most direct comparison with the results of the present experiment. Hogan \& Weston ( 1967 ) used a lucerne diet of very similar energy digestibility but their lucerne diet was a hay (i.e. sun-cured) compared with the high-temperature, artificially dried lucerne used in the present study. Hogan \& Weston (1967) studied the pattern of digestion within the alimentary tract using sheep fitted with a direct cannula into the abomasum. This allowed these authors to distinguish between digestion in the stomachs and in the intestines, but not to differentiate between digestion and absorption occurring in the small intestine from that taking place in the large intestine. In their experiment, Hogan \& Weston ( 1967 ) did not observe any effect of altering the physical form of the diet on the pattern of digestion within the alimentary tract. There were, however, several aspects of the preparation and feeding of the lucerne diet which probably contribute to the different results obtained in the two experiments. The method of drying - drying can affect the sites and extent of digestion of the energy and protein in forages (Beever et al. 1971); the lucerne was ground through a $3 \mathrm{~mm}$ screen and the pellets were offered at $3 \mathrm{~h}$ intervals, compared with a $2 \mathrm{~mm}$ screen and feeding twice daily in this experiment. Bickerstaffe, Noakes \& Annison (1970) have noted that infrequent feeding with pelleted diets increased net flow of digesta into the small intestine compared with the flow measured when feeding was frequent. Further experimentation will be required to determine which of these factors influences the change in the site of energy digestion of ground lucerne diets. It might also be noted that Hogan \& Weston ( 1967 ) used two markers $-{ }^{51} \mathrm{Cr}$-EDTA to indicate the movement of soluble substances and finely suspended particles, and lignin for the movement of the large particles of the digesta - and the abomasal digesta samples were obtained on 3 successive days by sampling at three intervals ( 30,90 and $150 \mathrm{~min}$ ) after feeding. In the present experiment total $24 \mathrm{~h}$ collections were made and chromic oxide was used as the marker.

The results of the present experiment with a high-temperature dried lucerne diet substantiate previously published results (Hogan \& Weston, 1967; Hinders \& Owen, 1968) which have shown the rumen to be the principal site of digestion of structural carbohydrate contained in forage diets (Tables 4, 5). Grinding and pelleting reduced the extent of digestion of these fractions within the rumen, in agreement with the results of Hinders \& Owen ( 1968 ), who showed a reduction from 90 to only $60 \%$ of the digestible fibre being degraded in the rumen when long lucerne was ground and pelleted.

The results from the present re-entrant cannula experiment directly quantify the effects of grinding and pelleting in altering the site of energy digestion - effects which had previously been indirectly postulated from studies on rate of passage (Blaxter $e t$ al. 1956), from measurements of fill in the digestive tract of slaughtered sheep (Pritchard \& Heaney, 1963) and from studies in rumen fill and digestion (Campling \& Freer, 1966). The results with the chopped and processed lucerne diets also suggest 
that the pattern of digestion of processed legumes within the alimentary tract may differ from that of grasses. Further study of digestion within the reticulo-rumen on processed forage diets is required. The rate of digestion of energy-yielding moieties in the rumen may have been increased by grinding the lucerne diet, but simultaneously the rate of passage from the rumen of partially digested particulate matter may also have been higher on the ground diet compared with the chopped diet (Table 3). Some measure of the extent of microbial synthesis in the rumen and the proportion of dietary nitrogen which may have reached the duodenum undigested may be gained from knowledge of the amounts of ribonucleic acid nitrogen entering the small intestine (Smith \& McAllan, I970). These determinations, to be reported in a later paper, indicate that an appreciably greater proportion of dietary protein entered the small intestine of sheep given the pelleted diet, compared with those found on the chopped and wafered diets. The finding that over $50 \%$ of the digested energy of the ground pelleted diet was digested by host cnzymes in the small intestine, and that the contribution of rumen VFA to the pool of energy metabolites was reduced and did not differ in molar composition from that obtaincd on the chopped diet, may at least in part explain the improved utilization of the dietary energy in the ground, pelleted compared with the chopped lucerne diet (Thomson \& Cammell, I972).

'The authors would like to record their thanks to Mr G. F. Brown, MRCVS, for the veterinary supervision of the sheep, to Mrs M. MacDonald for her assistance in their routine care and feeding, and to Miss B. Lumsden for analytical assistance.

One of us (D.J.T.) was on secondment from the Grassland Research Institute, Hurley.

\section{REFERENCES}

American Society of Agricultural Engineers (1967). Yb. Am. Soc. agric. Engrs p. 301 .

Balch, C. C. (1969). Proc. 3 rd gen. Mtg Eur. Grassld Fedn, Braunschweig p. 245.

Balch, C. C., Broster, W. H., Kook, J. A. F. \& Tuck, V. J. (1965). F. Dairy Res. 32, I.

Balch, C. C. \& Campling, R. C. (1965). In Physiology of Digestion in the Ruminant p. 108 [R. W. Dougherty, editor]. London: Butterworths.

Beardsley, D. W. ( I 964). F. Anim. Sci. 23, 239.

Beever, D. E., Thomson, D. J. \& Harrison, D. G. (1972). Proc. Nutr. Soc. 3r, 86A.

Beever, D. E., Thomson, D. J., Pfeffer, E. \& Armstrong, D. G. (1971). Br. Y. Nutr. 26, 123.

Bickerstaffe, R., Noakes, D. E. \& Annison, E. F. (I970). Proc. Nutr. Soc. 29, i A.

Blaxter, K. L. \& Graham, N. Mc. (1956). \%. agric. Sci, Camb. 47, 207.

Blaxter, K. L., Graham, N. Mc. \& Wainman, F. W. (1956). Br. \%. Nutr. xo, 69.

Brown, G. F., Armstrong, D. G. \& MacRae, J. C. (1968). Br. vet. F. 124, 78.

Bruce, J., Goodall, E. D., Kay, R. N. B., Phillipson, A. T. \& Vowles, L. E. (1966). Proc. R. Soc. B I66, 46.

Campling, R. C. \& Freer, M. (1966). Br. F. Nutr. 20, 229.

Corbett, J. L., Greenhalgh, J. F. D., McDonald, I. \& Florence E. (I960). Br. J. Nutr. 14, 289.

Crampton, E. W. \& Maynard, L. A. (1938). F. Nutr. 15, $3^{83}$.

Forbes, E. B., Fries, J. A. \& Braman, W. W. (1925). F. agric. Res, 31, 987.

Heaney, D. P., Pigden, W. J., Minson, D. J. \& Pritchard, G. I. (1963). F. Anim. Sci, 22, 752.

Hinders, R. G. \& Owen, F. G. (1968). \%. Dairy Sci. 5I, I253.

Hogan, J. P. \& Phillipson, A. T. (1960). Br. F. Nutr. I4, 147.

Hogan, J. P. \& Weston, R. H. (1967). Aust. F. agric. Res. 18, 803.

Leng, R. A. (1970). In Physiology of Digestion and Metabolism in the Ruminant p. 406 [A. T. Phillipson, editor]. Newcastle upon Tyne: Oriel Press.

MacRac, J. C. \& Armstrong, D. G. (1968). F. Sci. Fa Agric. 19, 578.

MacRae, J. C. \& Armstrong, D. G. (1969a). Br. F. Nutr. 23, 15. 
Vol. 28

MacRae, J. C. \& Armstrong, D. G. (I969b). Br. \%. Nutr. 23, 377.

Meyer, J. H., Gaskill, R. L., Stoewsand, G. S. \& Weir, W. C. (1959). F. Anim. Sci. 18, 336.

Meyer, J. II., Kromann, R. \& Garrett, W. N. (1965). In Physiology of Digestion in the Ruminant p. 262 [R. W. Dougherty, editor]. London: Butterworth.

Meyer, J. H., Weir, W. C., Jones, L. G. \& Hull, J. L. (Ig60). F. Anim. Sci. 19, 283.

Minson, D.J. (r963). F. Br. Grassld Soc. 18, 39.

Moore, L. A. (1964). Ұ. Anim. Sci, 23, 230.

Paladines, O. L., Reid, J. T., van Niekerk, B. D. H. \& Bensadoun, A. (1964). F. Nutr. 83, 49.

Pritchard, G. I. \& Heaney, D. P. (1963). Can. F. Anim. Sci. 43, 226.

Rodrigue, C. B. \& Allen, N. N. (1960). Can. 7 . Anim. Sci. 40, 23.

Smith, R. H. \& McAllan, A. B. (I970). Br. F. Nutr. 24, 545 .

Stcvenson, A. E. \& de Langen, H. (1960). N.Z. Fl agric. Res. 3, 314.

Thomson, D. J., Beever, D. E., Coelho da Silva, J. F. \& Armstrong, D. G. (1969). Proc. Nutr. Soc. 28, $24 \mathrm{~A}$.

Thomson, D. J. \& Cammell, S. B. (1972). Proc. Nutr. Soc. 3x, 88 A.

Topps, J. H., Kay, R. N. B. \& Goodall, E. D. (I 668). Br. Ұ. Nutr. 22, 26 I. 